\title{
A REVOLUÇÃO ESPANHOLA DE 1820: \\ Memorando sugerindo medidas que impedissem sua propagação em Portugal
}

Braz Augusto Aquino Brancato*

A restauração absolutista espanhola, levada a efeito coma derrogação da Constituição gaditana de 1812 , por Fernando VII em 1814, não chegou a se constituir, propriamente, num silenciamento daqueles que propugnavam pela existência de uma ordem constitucional na Espanha.

Neste sentido, como é bem conhecido, o sexênio absolutista (18141820) foi um período em que proliferaram as tentativas de fazer com que o sistema constitucional fosse restaurado e, sobretudo nos últimos três anos, as inquietações revolucionárias foram aumentando. Era cada vez maior o número de pessoas que deixavam de acreditar que a sorte da Espanha seria mudada: o governo absoluto de Fernando VII já mostrava claramente não ser capaz de resolver os graves problemas que assolavam uma Espanha que submergia devido a uma administração incompetente e a uma economia debilitada, como fica bem ressaltado no of ício $^{1}$ de D. José Luís de Sousa, Ministro português em Madrid, que, comentando a situação espanhola escreve:

“...A Constituição estabelecida pelas Cortes cheia de defeitos não teve sem dúvida a aceitação da Nação Hespanhola, mas não deixou de espalhar certas ideas liberais que na epoca presente prevelecem em quasi toda a Europa, e assim a arbitrariedade e o despotismo que este Governo tem mostrado nas frequentes prizões e desterros de hum sem numero de individuos

\footnotetext{
${ }^{1}$ Ofício n 257 ( 2 a via), de 5 de março de 1820, enviado a Tomás Antonio de Vila Nova Portugal. Arquivo Nacional da Torre do Tombo (ANTT) - espólio de António Saldanha da Gama, M\%4
} 
tem necessariamente exaltado muito os espiritos descontentes pela falta de systhema de Governo, e o abandono de todos os ramos da administração publica. A influencia de alguns Criados Particulares de dos validos d'El Rei aos quais o publico tem dado o nome de Camarilha tambem tem concorrido muito para o descontentamento da Nação, por que a maior parte d'aquelles individuos sendo homens de baixas idéias [... só attendem aos seus interesses..."

Assim, naqueles anos finais do "Sexênio absolutista", o ambiente vai se tornando cada vez mais propício para a eclosão de um movimento revolucionário de cunho liberal: começava a surgir um espaço para que uma proposta de mudança viesse a ser melhor recebida que em anos anteriores.

Em tais circunstâncias, próprias do período, não faltaram os pronunciamentos que, como destaca Stanley Payne, ${ }^{\hat{2}}$ não "passaram de pequenas sublevações abortadas contra o absolutismo" e que finalmente "conduziram à primeira rebelião vitoriosa em 1820 ", que veio a configurar-se, esta sim, na culminação bem sucedida de um processo de oposição ao absolutismo fernandino.

Com efeito, ao finalizar o ano 1819, o Bourbon espanhol, numa desesperada tentativa de retomar as colonias americanas, tratou de organizar um exército que deveria transpor o Atlântico. Para tal reuniu, na Andaluzia, aproximadamente 20.000 homens em armas. Tais homens compunham, ainda segundo Payne ${ }^{3}$, "o único setor do exército minimamente preparado para o combate, que tinham sido assentados perto de Cádis, em insanos e primitivos acampamentos, onde foram sendo dizimados pelas doenças", além de carecerem "quase que completamente de qualquer desejo autêntico de lutar contra os venezuelanos e colombianos, empresa que, naquele momento, a sociedade espanhola julgava totalmente quimérica". A tudo isto deve ser acrescentado o fato de que tais homens deveriam ser embarcados na flotilha que o governo espanhol havia adquirido da Rússia de Alexandre I e, que não reunia as mínimas condiçõos de empreender uma viagem transatlântica. Na verdade sua simples saída do porto já se configurava num verdadeiro perigo.

$\hat{E}$, pois, dentro de tal contexto que, no dia 1 o de janeiro de 1820 , eclode em Las Cabezas de San Juan um levantamento com o intuito de restaurar a Constituição espanhola de 1812: finalmente um pronunciamiento lograva êxito. O Ten. Cel. Rafael del Riego iniciava assim o movimento revolucionário

\footnotetext{
${ }^{2}$ Los Militares y la Polftica en la España Contemporânea, Paris, Ed. Ruedo Ibérico, 1976 , p. 15.
}

${ }^{3}$ Ejército y Soedad en la España Liberal (1808-1936), Madrid, Akal Ed., 1977, pp. 28-29. 
que, aos poucos, iria se alastrando por toda a Espanha fazendo com que, finalmente. no dia 7 de março do mesmo ano. Fernando VII jurasse a Constituição que ele mesmo havia derrogado quando de sua volta do "cativeiro" de Valençay

Tal ocorrência, como é facilmente compreensível, preocupou aqueles governos que pretendiam, a qualquer custo, manter o liberalismo afastado de seus povos. no entanto, o "diabólico" movimento revolucionário espanhol reascendia uma chama que a "política dos Congressos" da Europa restaurada tratava de manter apagada. Para os opositores do liberalismo se apresentava, então, um sério problema: o "contágio" deveria ser evitado!

E dentro desta linha de preocupações que se insere o documento a seguir transcrito e que, embora não datado nem assinado, tem especial interesse para mostrar o tipo de preocupação que vai despertar especialmente em Portugal que, não só pela vizinhança se tornava facilmente vulnerável, como também pela sabida aproximação existente entre lib̉erais espanhóis e portugueses e, ainda mais, Portugal, naquele momento, vivia uma situação extremamente propícia para que se disseminasse, também lá, a revolução. A Corte seguia no Rio de Janeiro e com isto todo um conjunto de problemas a se refletir diretamente numa população descontente.

Tal sitaução se deduz da própria leitura do documento em pauta e é reforçada por inúmeros outros, como é o caso do ofício enviado de Lisboa, no dia 15 de janeiro daquele ano de 1820, por D. Manuel de Lardizabal y Montoya ao Secretário de Estado da Espanha, Duque de San Fernando ${ }^{4}$, onde se pode ler:

“...En las actuales circunstancias en que Portugal se puede considerar como una colonia del Brasil, hay gran numero de descontentos, y á la verdad no sin algun motivo, pues la Corte del Janeiro no trata sino de sacar todo el provecho que pueda de este país, y asi es que de este Erario se hacen continuas remesas de dinero; lo que vá ya causando atrasos en los pagos de sueldos e empleados civiles y militares [... I Todo esto, el temor que la proximidad haga se propague el espiritu de insurreccion..."

Fica, ainda, bem claro no documento logo transcrito, que dentre as preocupações que levam o Autor a aconselhar medidas a serem tomadas, sobressai o temor de que, como na Espanha, a tropa portuguesa viesse a se sublevar e promover a revolução.

${ }^{4}$ Archivo Histórico Nacional Madrid (AHNM), Sección de Estado, Legajo 3081, caja 2. 
Finalmente, parece interessante destacar que tal document $0^{5}$ se encontra justamente entre os papéis de Antônio Saldanha da Gama que viria a ser o 1 . Conde de Porto Santo e que exerceu as funções de Enviado Extraordinário e Ministro Plenipotenciário de Portugal na Espanha ${ }^{6}$ e que em 1825 seria nomeado Secretário dos Negócios Estrangeiros de seu país.

${ }^{5}$ ANTT. Espólio de António Saldanha da Gama, Mํ.4, n 98.

${ }^{6}$ Com nomeações em 22 de janeiro de 1819 e 23 de abril de 1821, como o indica Raul Alberto de CAMPOS in: Relą̧ôes Diplomáticas do Brasil de 1808 a 1912, Rio de Janeiro, Typ. do "Jornal do Commercio, 1913, p. 68.

*Departamento de História. Pontifícia Universidade Católica do Rio Grande do Sul 90620 Porto Alegre - RS. 


\section{TEXTO DO MEMORANDO:}

"Como o fito dos demagogos espanhoes e talves dos de outras nações para revolucionar Portugal, he influir no exercito o espirito revolucionario: creio conviria ao governo adoptar as seguintes medidas:

$$
1 \text { á }
$$

Ter o cuidado em examinar os passos de estrangeiros desconhecidos, que chegão a qualquer parte do Reino, particularmente naquelles lugares em que ha tropa.

\section{2 a}

Vigiar do mesmo modo sobre os portugueses que chegão de fora; e que são de hum caracter duvidozo.

Ter paga exactamente a tropa; e a esse fim deve o governo em conciencia e mesmo por bem entendida fidelidade a El Rey e á Patria, declarar para o Rio de Janeiro, que nas criticas circunstancias em que se acha o Reino, não podem aceitar saque algum do Brasil, pois se os aceitarem ficará a tropa sem ser paga; e o governo está persuadido q̃ he menor mal que o Erario do Rio de Janeiro soffra o discredito de vêr as suas letras protestadas do que perder El Rey Portugal: o que sucedera não se pagando a tropa. $\mathrm{E}$ he tanto mais do dever daquelle governo tomar esta resolução, quando se considera que recahe só sobre elles a responsabilidade de se perder o Reino por falta de pagar o exercito; mas a responsabilidade dos saques protestados, deve recahir sobre quem administra o Erario do Rio de Janeiro tão mal e iniquamente, que faz saques sobre o de Lisboa sem lhe importar que a tropa seja ou não paga. Não pode duvidar fallar deste modo na hora do perigo, quem tem verdadeiro zelo e pa- 
triotismo, e declarar mais, que se assim não querem, nomeem outro em seu lugar.

Empregar officiaes de confiança; capacidade e que sejão bem vistos no exercito para que em conversação inspirem na officialidade que tem mais influencia no Exercito os sentimentos e ideas que vou explanar sobre os 4 seguintes pontos.

= Desprezo para a officialidade espanhola pelo abdominável comportamento em todos os tempos = Desprezo para o governo espanhol em geral seja o de Carlos 3 ? [certamente o A. equivocou-se colocando $3 \%$ ao invés de 4 ? Fernando 70, ou das Cortes, pois todos produzirão immensàs calamidades na Espanha e em Portugal = Que qualquer governo venha a ter Espanha sempre olhará arrogantemente Portugal como huma conquista que lhe pertence $=$ Que qualquer parte Portugal tomar na Revolução da Espanha seria para elle ruina certa; e sendo expectador tranquillo dos acontecimentos, pode com o tempo tirar partido daquella revolução conservandose o exercito em bom pé =

$O$ desprezo para o officialidade espanhola he justamente excitado pelos seguinte factos = Nunca forão capazes de disciplinar hum exercito, antes reinou sempre nelles a maior indisciplina, e huma total desordem na sua organização - Foi o exercito que prendeu as Cortes e instalou Fernando 70, e he o mesmo exercito que tem agora / bem se pode dizer / feito prisioneiro o Rey, e parte delle quer instalar as Cortes e outra não - Que os officiaes condusirão, e neste ultima revolução com uma perfidia indigna que deshonra o carater militar levando a imprudencia e falta de todos os sentimentos de honra ao ponto de confessar em huã proclamação o Conde de Abisbal que tinha sempre enganado El Rey - Que esta perfidia he tanto mais infame para militares, quando se vê que ella foi gerada pela cobardia de evadir a hir conservar a sua patria as possessões da America, decretadas pèla contituição que elles pretendem restabelecer como parte integrante da Monarquia, e sem novas expediçðes, nem se poderão recuperar as rebelladas, nem conservar as que ainda estão sujeitas! - Que o outro O'Donnel protestou a El Rey que hia derramar á ultima gota do seu sangue para pôr termo á insurreição, e logo q̃ se poz a frente do exercito proclamou a Constituição das Cortes - Que para levar ao fim a insurreição até enganarão os soldados que não queriam as Cortes, o que cauzou as desgraças de Cadiz - Tambem não deve esquecer quanto em outro tempo, os generaes Palafox e Morla deslustrarão os seus primeiros feitos declarandose porfim Bonapartistas.

Desprezo para o Governo espanhol. - Duas vezes no governo de Carlos 
$4^{\circ}$ os espanhoes invadiram Portugal como vanguarda dos francezes Fizerão se os infames Tratados de Madrid e Fontannebleau em que Portugal era ann. quilado.

No governo das Cortes Elio fez a capitulação de Montevideo e tendo antes pedido as nossas tropas como auxiliares. fez a infamia de estipular em hum dos artigos da capitulação, que uniria as suas tropas com as de Buenos Ayres para nos expulsar do territorio que occupavamos, se recusassemos evacuar Encurraladas as Cortes em Cadiz, e tendo perdido toda a Espanha pela sua obstinada ignorancia de saberem organizar hum exercito; perderião tambem aquelle canto que occupavão, se as vitorias do exercito anglo-lusitano, não the reconquistassem toda a Espanha. $\bigcirc$ pago que nos derão as cortes foi chamarnos serviles, e não nos restituirem Olivença.

No governo de Fernando 7 p̣ pretendeu o Ministério espanhol fazer reviver o infame Tratado de Fontainebleau, e indemnisar a Rainha da Etruria em Portugal Apesar de assignar o Tratado de Viènna em que se estipulou a restituição de Olivença obstinouse o governo espanhol em não fazer a entrega Armou subrepticiamente huã intriga nos gabinetes das Potencias alliadas, para que estas consentissem em que os espanhoes se apoderassem de Portugal por termos occupado Montevideo p! nossa propria defesa Tendo para esse fim pedido dolosamente a mediação das Potencias. não quiz estar pelas estipulações que ellas propuserão como justas, e preparava a invencivel armada para nos fazer evacuar por força Montevideo; mas esta expedição servio somente para fazer evacuar Fernando 70 o throno, e a corja que o rodeava os lugares que indignam ${ }^{\text {te }}$ occupavão

Qualquer governo venha a ter Espanha sempre tratara Portugal como huã conquista que lhe pertence Tendo experimentado como os Reys proximos parentes e as Cortes tratarão Portugal: não se pode esperar que as novas Cortes ou outro governo perca a idea arrogante de o subjugar por força ou manha fundada em sedução. Os demagogos espanhoes ja formaram castellos em Espanha e blasonão que hão de seguir o trilho dos franceses invadindo e saqueando os povos visinhos com palavras de protecção e liberdade; e tem a temeridade de dizer nos cafés de Madrid que assim farão a Portugal, para empregarem o exercito espanhol sem se lembrarem $\tilde{\mathrm{q}}$ os nossos soldados em varias batalhas, e particularm ${ }^{\text {te }}$ na de Tousouse a força de bofe tões e coronhadas de espingarda fizeram tornar os soldados espanhoes aos postos q̃ desertavão!

A revolução da Espanha deve ter mui differentes effeitos da de França, porque os principios activos de huma e outra são de huma differente natureza e quasi opposto. e huma povoação facil de recrutar e apta a formar bons soldados em pouco tempo Em Espanha a officialidade he detestaval em todos os sentidos Em França e povoação he compacta. amalgamada em costumes. e sem notavel opposição entre huãs e outras provıncıas Em Espanha os di- 
ferentes Reinos são divididos huns dos outros quasi por desertos: cada hum tem seus usos e privilegios particulares de que he zeloso; e as differentes povoações detestam se entre si - Em França a capital tem huma povoação imensa, capaz de dar direção a todo o Reino - A Espanha tem huma capital com uma povoação quasi igual á de outras cidades do Reino - A França tendo adquirido em maior grao as pretendidas perniciosas luzes do seculo, organizou previamente por meio de mil pennas envenenadas a immoralidade o atheismo e a incredulidade civil e religiosa, que são os elementos mais fortes da insubordinação e de um energumeno espirito revolucionario - Em Espanha a grande massa do povo e hum grande numero das classes superiores respeitão a moralidade e a religião, e não estão como os francezes iniciados nọ misterios da insubordinação - Em França a revolução foi feita pelo povo seduzido e forçado por hum grande numero de malvados que formavão differentes clubs e erão versados na arte revolucionaria. Em Espanha a revolução foi feita por parte do exercito para não se embarcar.

Differenças tão essenciaes nas circunstancias das duas revoluções necessariamente hão de produzir differentes resultados. Se as Cortes ou qualquer outro governo em Espanha quizerem imitar os francezes e consolidar a sua revolução por meio de huma guerra externa acharão ainda mais difficuldade em formar hum exercito bem organizado do que encontrarão as primeiras Cortes, quando a unanimidade da nação era a favor da guerra. Maior difficuldade haverá em expedir tropas para America; e se as não mandarem perderão todas possessões transatlanticas: perda que necessariam ${ }^{\text {te }}$ ha de despopularizar muitissimo o governo q̃ o fizer.

Podese pois quase adivinhar que os resultados da revolução de Espanha serão - Descontentamento continuo nos povos de todos os governos que os partidos fizerem succeder huns a outros - Escacez progressiva de finansas Dispersão do exercito por falta de meios de o pagar, e porã as Cortes o hão de temer - Formação de guerrillas despojando as povoações - E provavelmente huã separação-dos Reinos que compoem a Monarquia espanhola formando cada hum delles governo a seu modo, e talvêz no prịncipio alguma especie de federação entre si; mas tal federação não pode durar muito tempo tanto pelas dissençōes que acompanhão sempre governos federativos, como porque a França / particularm tẹ se ha nella alguma revolução como he muito recear / procura ser chefe e protectora daquella federação para a engolir aos pedaços - Os francezes são mestres nesta tactica, e tem meios superabundantes para o pôr em pratica.

Qualquer parte Portugal tomasse na Revolução de Espanha seria pa elle huma ruina certa; e sendo expectador tranquillo dos acontecitos, pode com o tempo tirar partido daquella revolução conservando o exercito em bom pé. 
Se Portugal tomasse qualquer parte na revolução de Espanha deveria necessariamente correr a sorte daquelle desgraçado paiz, q̃ não pode ser outra se não soffrer calamidades sobre calamidades, como ja expuz.

He verdade que Portugal tambem esta soffrendo alguns incomodos, mas estes não tem comparação com os males que a revolução vai sem duvida produzir em Espanha com divisões e reacções de partidos, guerra civil, saques de povoações e anarquia que devem ser os funestos resultados do conflicto entre os diversos poderes que dominão agora em Espanha, os quaes para terem influencia no governo precisão destruirse huns a outros. Estes poderes são - a Junta de Madrid, as Juntas estabelecidas em diversas provincias, algumas das quaes tem por si só abolido impostos e declarado q̃ não se dissolverão em quanto as Cortes não se ajuntarem - $\mathrm{O}$ club dos liberaes em Madrid alimentado pelas sociedades secre tas da França, Alemanha, Inglaterra, etc. - $\mathrm{O}$ exercito $\tilde{\mathrm{q}}$ fez a revolução, e não ha de mansamente deixar annullar o seu poder - $\mathrm{O}$ partido realista em que estão os dois estados da nobreza e clero e grande parte do povo em que este ultimo ainda tem grande influencia e finalm ${ }^{\text {te }}$ as Cortes quando se ajustarem.

Se pois Portugal ficar tranquillo, sem divida El Rey em lhe chegando a noticia do $\tilde{\mathrm{q}}$ se passa em Espanha ha de certamente completar o Ministerio com pessoas q̃ não sejão moribundas como os Ministros passados, e dar providencias adequadas asaber fazer o berço da Monarquia, $\tilde{q}$ o novo Ministerio q̃ se formar bem ha de conhecer, $\tilde{q}$ he tambem a base da sua força.

Governandose bem Portugal e o resto da Monarquia he indubitavel q̃ se hão de offerecer ocasiōes opportunas de tirar vantagem da confusão que vai reinar em Espanha; pois sempre o bom governo de hum paiz tira vantagem do mao governo dos vesinhos. 